\title{
Support for Caregiver
}

National Cancer Institute

\section{Source}

National Cancer Institute. Support for Caregiver. NCI Thesaurus. Code C116699.

Any type of assistance, including emotional, financial, and spiritual, given to a caregiver. 